\title{
Review
}

\section{Host response to Brucella infection: review and future perspective}

\author{
Mohamed G Elfaki ${ }^{1,2}$, Alwaleed Abdullah Alaidan ${ }^{1}$, Abdullah Abdulrahman Al-Hokail ${ }^{2,3}$ \\ ${ }^{1}$ Department of Infection and Immunity, King Faisal Specialist Hospital and Research Centre, Riyadh, Saudi Arabia \\ ${ }_{3}^{2}$ Alfaisal University College of Medicine, Riyadh, Saudi Arabia \\ ${ }^{3}$ Department of Medicine, King Faisal Specialist Hospital and Research Centre, Riyadh, Saudi Arabia
}

\begin{abstract}
Brucellosis is a zoonotic and contagious infectious disease caused by infection with Brucella species. The infecting brucellae are capable of causing a devastating multi-organ disease in humans with serious health complications. The pathogenesis of Brucella infection is influenced largely by host factors, Brucella species/strain, and the ability of invading brucellae to survive and replicate within mononuclear phagocytic cells, preferentially macrophages $(\mathrm{M} \phi)$. Consequently, the course of human infection may appear as an acute fatal or progress into chronic debilitating infection with periodical episodes that leads to bacteremia and death. The existence of brucellae inside $\mathrm{M} \phi$ represents one of the strategies used by Brucella to evade the host immune response and is responsible for treatment failure in certain human populations treated with anti-Brucella drugs. Moreover, the persistence of brucellae inside $\mathrm{M} \phi$ complicates the diagnosis and may affect the host cell signaling pathways with consequent alterations in both innate and adaptive immune responses. Therefore, there is an urgent need to pursue the development of novel drugs and/or vaccine targets against human brucellosis using high throughput technologies in genomics, proteomics, and immunology.
\end{abstract}

Key words: brucellosis; pathogenesis; immunity, Saudi Arabia.

J Infect Dev Ctries 2015; 9(7):697-701. doi:10.3855/jidc.6625

(Received 30 January 2015 - Accepted 05 May 2015)

Copyright ( $\odot 2015$ Elfaki et al. This is an open-access article distributed under the Creative Commons Attribution License, which permits unrestricted use, distribution, and reproduction in any medium, provided the original work is properly cited.

\section{Introduction}

Brucellosis is a zoonotic and contagious infectious disease caused by bacteria of the genus Brucella. There are 10 species of Brucella that have been classified on the basis of primary host specificity, biochemical characteristics, and antigenic component [1]. Among the known species of Brucella, $B$. melitensis, B. abortus, and B. suis are the most pathogenic to humans [2]. However, in Saudi Arabia, $B$. suis does not exist due to the lack of its natural animal reservoir, the swine species, leaving $B$. melitensis and $B$. abortus as the two most common brucellae that cause human infection in this region [35]. The bacterium is a small, Gram-negative, nonmotile coccobacillus adapted to intracellular living within host mononuclear phagocytic cells $[1,6]$. The bacterium infects primarily ruminant animals and is transmitted to humans through contact with infected animals, including handling of infected carcasses, consumption of unpasteurized milk or milk products, or, in rare cases, through inhalation of aerosols from infected specimens $[7,8]$. Thus, humans are accidental hosts of brucellosis. Transmission is also possible by inhalation of fomites, as brucellae have the ability to survive in dusty environments and free-range rearing conditions for several months without losing infectivity [9]. In rare cases, hospital-acquired infection may occur [10] due to the volatile nature of brucellae and a low dose requirement to cause infection. Thus, the spread of brucellae increases public panic and anxiety worldwide.

Most of the infected animals in Saudi Arabia are inhabitants of rural areas where intense human interaction with animals coupled with the nomadic lifestyle of the inhabitants favor the transmission of brucellae [11]. The natural animal reservoirs for brucellae in this region include camels, cattle, sheep, and goats. The disease is economically important in farm animals and will be a major public health problem worldwide unless stringent control measures are undertaken in the livestock industry [12]. The prevalence rate of brucellosis has increased recently in traditionally endemic regions such as the Mediterranean basin countries, the Arabian Peninsula, South America, and Southeast Asia [13]. The disease annually infects 500,000 humans worldwide, a number that may be higher in depressed regions of the world. In Saudi Arabia, however, the incidence rate of 
brucellosis has risen (70 in every 100,000), and the disease prevalence is considered among the top five communicable diseases as reported by the Saudi Ministry of Health (MOH) (http://www.moh.gov.sa).

\section{Pathogenesis and clinical presentation}

Brucella has the propensity to localize inside $\mathrm{M} \phi$ $[6,14]$ of the liver, spleen, bone marrow, uterus, heart, and brain with protean clinical manifestations [15]. The disease is characterized by undulant fever, arthritis, spondylitis, endocarditis, osteomyelitis, and hepatosplenic abscesses or brain abscesses in rare events [16,17]. In animals, however, brucellosis is characterized by spontaneous abortion at late gestation, orchitis, undulant fever, and infertility, leading to severe economic losses of farm animals [7].

The adaptation of Brucella to live inside $\mathrm{M} \phi$ [18] is managed by its ability to block receptors for innate immunity [19], inhibit phagolysosome fusion, inhibit apoptosis, and downregulate antigen presentation [20], which collectively leads to their escape from effector immune responses [21]. However, the propensity of Brucella to localize inside reticuloendothelial cells of parenchymatous organs, especially the liver and the spleen [22], is responsible for the consequential formation of granuloma in these organs. In conditions of immune challenges, the hidden brucellae will be released from their harbored sites with consequent relapse of infection and the appearance of chronic fatigue. Episodes of the systemic release of these brucellae may result in the development of bacteremia with consequent expression of undulant fever, splenomegaly, hepatomegaly, endocarditis, meningitis, arthritis, or osteomyelitis [16, 17] in most chronic cases. Based on these broad and serious clinical sequelae where multi-organ systems are implicated [15], the diagnosis and control of brucellosis pose a serious challenge to healthcare professionals.

\section{Cell response to Brucella infection}

The intracellular nature of Brucella organisms makes it difficult for these bacteria to be completely eliminated by the host cellular responses [20] or be eradicated by antimicrobial drugs [23, 24]. Thus, brucellae evade the host's cellular response with subsequent tissue retention, and relapse of infection ensues [21]. The mechanistic events involved in the cascade of this process are not fully understood and require further study. However, previous studies showed that several regulatory molecules secreted by $\mathrm{M} \phi$ may contribute to the intracellular survival of brucellae in murine $\mathrm{M} \phi$. Macrophage-derived cytokines such as interleukin 1 (IL-1), IL-12, and tumor necrosis factor alpha (TNF- $\alpha$ ) contribute to the control of early Brucella spp. infection via the IFN- $\gamma$ pathway $[25,26]$. Indeed, IFN- $\gamma$ has been reported to reduce the intracellular growth of Brucella by upregulating both $\mathrm{M} \phi$ effector function and the secretion of TNF- $\alpha$ and iron molecules [27]. Other regulatory molecules produced by $\mathrm{M} \phi$ such as reactive oxygen intermediates and nitric oxide have been reported to control the growth of B. abortus [28]. In essence, the persistence of brucellae in $\mathrm{M} \phi$ is broadly attributed to failure of phagolysosomal fusion [29, 30], inhibition of the oxidative burst $[31,32]$, or to the synthesis of $\mathrm{Cu}-\mathrm{Zn}$ superoxide dismutase [33], which inactivates oxygen radicals and promotes the intracellular survival of brucellae inside the $\mathrm{M} \phi$ niches. A recent study by Barrionuevo et al. [34] demonstrated that $B$. abortus utilizes its lipoproteins to inhibit the monocytes/macrophages activation mediated by IFN- $\gamma$ and to subvert host immunological responses. Consequently, the marker for $\mathrm{M} \phi$ activation (FcyR1, CD64) was downregulated and no Fc $\gamma$ R1mediated phagocytosis ensued.

In addition to the role of $\mathrm{M} \phi$ in immunity, $\mathrm{T}$ cell subsets play a major role in the resolution of infection due to Brucella spp. $\mathrm{CD}^{+} \mathrm{T}$ cells secrete potent cytokines such as IFN- $\gamma$ and IL-10 that are known, respectively, to enhance protection or exacerbate infection due to brucellae [35-37]. The precise role of $\mathrm{T}$ cells in protection against Brucella infection has been unequivocally shown in studies using adoptive transfer [38] and gene knockout experiments [39]. In the murine model of infection [38], $\mathrm{CD} 4^{+} \mathrm{T}$ lymphocytes have been demonstrated to exert their protective effect by the production of IFN- $\gamma$, which activates rodent $M \phi$ to halt the replication of intracellular brucellae [37]. The effector molecules in killing brucellae by IFN- $\gamma$-activated $M \phi$ were related to the production of reactive oxygen intermediates but not to nitric oxide [28]. Regulation of IFN- $\gamma$ production in this process is mediated by the cytokines TNF- $\alpha$ and IL-12 [40], which were both secreted by activated $\mathrm{M} \phi$. In contrast, the counter-regulator of IFN- $\gamma$ production, IL-10, has been demonstrated to exacerbate infection due to $B$. abortus [41]. Based on these studies, both $\mathrm{CD}^{+}$and $\mathrm{CD}^{+} \mathrm{T}$ cells were implicated in protection against brucellosis in the murine model of Brucella infection. While $\mathrm{CD}^{+}{ }^{+} \mathrm{T}$ cells exert their effect via cytokine secretion, cytotoxic $\mathrm{CD}^{+} \mathrm{T}$ cells eliminate infection by lysing autologous M $\phi$ infected with Brucella spp. Recent studies by Cha 
et al. [42] corroborated the above findings by demonstrating increased production of IFN- $\gamma$ in mice inoculated with $B$. abortus outer membrane proteins compared to animals inoculated with whole live bacteria.

In humans, little is known about the immunological control of $B$. melitensis infection. Previous studies by Zaitseva et al. [43] demonstrated the expression of Th1 cytokines in vitro by $\mathrm{CD}^{+}$and $\mathrm{CD}^{+} \mathrm{T}$ cells stimulated with heat-inactivated $B$. abortus. There have been no in vivo studies to corroborate these findings, due to restrictions imposed on the study of human subjects as well as ethical conduction rules in the study of human models. However, a recent study by our group [44] demonstrated an increased production and expression of transforming growth factor beta 1 (TGF- $\beta 1$ ) in sera and peripheral mononuclear blood cells (PMBCs) of patients with brucellosis. The increased TGF- $\beta 1$ production in these patients correlated well with depressed $\mathrm{T}$ cell proliferation and IFN- $\gamma$ production. On the basis of the above studies, it is obvious that Brucella infection causes secondary immunosuppression. However, the extent of immunosuppression in humans is difficult to evaluate due to patient dropout, ignorance of most patients about the importance of subsequent medical exams or tests, and the hidden medical history of patients suspected with chronic debilitating infections. Thus, brucellae constitute a major challenge to physicians and a threat to infected humans by evading the host immune response. The cellular cascade and mechanistic events involved in the generation of human infection are not fully understood.

\section{Humoral response to Brucella infection}

Antibodies of the IgG, IgM, or IgA classes may play a role in protection against brucellosis. AntiBrucella antibodies are proteins that cause agglutination, complement fixation, and precipitation when reacted with their homologous antigens [45] derived from brucellae. Most of the reactive antibodies were elicited by Brucella lipopolysaccharide (LPS) rather than by cytoplasmic proteins. Indeed, IgM antibodies against Brucella LPS were the first to appear following infection and rise gradually during the course of acute infection. In contrast, IgG antiBrucella antibodies appeared later after the onset of infection and were likely provoked by Brucella cytoplasmic proteins. On this basis, most of the available serological tests were based on LPS to differentiate between infected and uninfected hosts.
For cytoplasmic proteins, there is no single antigenic determinant that differentiates between infected humans and naturally infected animal hosts. Thus, the humoral response of humans to Brucella infection is different from that exhibited in animals, the natural reservoirs for brucellosis. A recent study that used protein microarrays [46] supported this notion and highlighted the importance of certain antigens as potential markers for each host response and disease pathogenesis. However, the differential power of these antigens in the differentiation of brucellae from their closely related bacteria was not reported by these investigators [46].

It is well known that anti-Brucella antibodies have the potential to cross-react with antibodies raised against heterologous Brucella strains or against some enteric bacteria. Cross-reactions in serum agglutination have been observed in infections caused by some enteric bacteria [47]. This cross-reactivity hampered the interpretation of many of serological tests used in the diagnosis of brucellosis [48]. The situation is worsened in farm animals vaccinated with the live-attenuated Rev1 vaccine, which makes it difficult to differentiate between vaccinated and infected animals [49]. In humans, the use of serological assays had complicated the clinical differentiation between acute, chronic, or chronic persistent forms. Thus, identification of key antigenic determinants among strains of Brucella spp. that do not cross-react with other bacteria is crucial for appropriate diagnosis. However, efforts to develop recombinant antigens for Brucella have been initiated with the goal to use them as subunit vaccines or purified antigens for definitive diagnosis [50]. Recently, unpublished proteomic data presented by Elfaki et al. at the $115^{\text {th }}$ General Meeting of the American Society for Microbiology (May 30-June 2, 2015), holds promise as diagnostic markers for the differentiation of Brucella species and strains.

\section{Future research perspectives}

Since the host response to Brucella is largely mediated by immune cells, elucidation of common proteomes elicited by peripheral blood mononuclear cells of infected patients as well as proteomes expressed by infecting brucellae are imperative to define both drug and vaccine targets against brucellae. A recent study in our laboratory showed a resolution of $\geq 600$ spots per Brucella strain with a minimum of $88 \%$ homogeneity (Elfaki et al., unpublished data). Marked quantitative and qualitative changes were observed in Brucella protein patterns measured by 
principal component analysis (PCA) and hierarchical cluster analysis. Furthermore, most of the differential peptides studied thus far were involved in cell metabolism, cell proliferation, and immune regulation (Elfaki et al., unpublished data). The goal of our current study is to elucidate markers implicated in microbial pathogenesis, disease progression, and immune regulation of Brucella infection. However, further research is needed to dissect the cellular pathways during Brucella infection. Of major interest, studies on the role of microRNAs in $\mathrm{CD}^{+}$or $\mathrm{CD} 8^{+} \mathrm{T}$ cell responses mounted against infection with brucellae. Such information is vital to define the regulatory role of microRNAs in phagocytosis or antigen presentation by either $\mathrm{M} \phi$ or dendritic cells infected with brucellae. Other points of interest that complement our current knowledge include the role of brucellae in the induction of inflammasomes, nuclear factor kappa-light-chain-enhancer of activated B cells $(\mathrm{NF}-\kappa \mathrm{B})$, toll-like receptors (TLR), and $\mathrm{T}$ regulatory cells. The outcome of the aforementioned prospective is to define conditions that elicit infection, inflammatory response, bacterial colonization and clearance, disease progression, and protection by immune effector cells. Unfortunately, most of the available data on immunity to brucellosis were collected from the murine model of infection. However, the response of murine species to Brucella infection is completely incompatible with responses encountered in the natural hosts of Brucella, such as ruminant animals, or even with that seen in accidental hosts such as humans. All of these factors led to controversial interpretations when comparing the animal response to that encountered in humans. Therefore, there is an urgent need to develop an animal model compatible with human brucellosis. In our judgment, unless the above research issues are well defined, no vaccine is possible against human brucellosis under these adversaries.

\section{Acknowledgements}

The authors would like to thank King Abdulaziz City for Science and Technology (KACST) for financial support of our research on brucellosis (grant \# AT-24-32) and the King Faisal Specialist Hospital and Research Centre for accommodating our work.

\section{References}

1. Ficht T (2013) Brucella taxonomy and evolution. Future Microbiol 5: 859-866.

2. Corbell MJ (1989) Brucellosis: Epidemiology and prevalence worldwide. In Brucellosis: Clinical and Laboratory Aspects, Young EJ, Corbel MJ, editors. Boca Raton: CRC Press. 2540 .
3. Assad AM, Alqahtani JM (2012) Serological and molecular diagnosis of human brucellosis in Najran, Southwestern Saudi Arabia. J Infect Public Health 5: 189-194.

4. Elfaki MG, Al-Hokail AA, Nakeeb SM, Al-Rabiah FA (2005) Evaluation of culture, tube agglutination, and PCR methods for the diagnosis of brucellosis in humans. Med Sci Monit 11: MT69-74.

5. Elfaki MG, Uz-Zaman T, Al-Hokail AA, Nakeeb SM (2005) Detection of Brucella DNA in sera from patients with brucellosis by polymerase chain reaction. Diag Microbiol Infect Dis 53: 1-7.

6. Gao G, Wang Y, Chen Z, Xu X, Xu J (2013) Brucella virulence mechanisms and implications in novel vaccines and drugs. Crit Rev Eukaryot Gene Expr 23: 49-64.

7. Enright FM (1990) Animal brucellosis. In Nielsen K, Duncan Jr, editors. Boston: CRC Press. 301-320.

8. Moreno E, Moriyon I (2002) Brucella melitensis: a nasty bug with hidden credentials for virulence. Proc Natl Acad Sci U S A 99: 1-3.

9. Aune K, Rhyan JC, Russell R, Roffe TJ, Corso B (2012) Environmental persistence of Brucella abortus in the Greater Yellowstone Area. J Wildlife Management 76: 253-261. doi: 10.1002/jwmg. 274.

10. Yagupsky P, Peled N, Riesenberg K, Banai M (2000) Exposure of hospital personnel to Brucella melitensis and occurrence of laboratory-acquired disease in an endemic area. Scand J Infect Dis 32: 31-35.

11. Cooper CW (1992) Risk factors in transmission of brucellosis from animals to humans in Saudi Arabia. Trans R Soc Trop Med Hyg 86: 206-209.

12. Refai M (2002) Incidence and control of brucellosis in the Near East region. Vet Microbiol 90: 81-110.

13. Gul ST, Khan A (2007) Epidemiology and epizootology of brucellosis: a review. Pak Vet J 27: 145-151.

14. Smith LD, Ficht TA (1990) Pathogenesis of Brucella. CRC Crit Rev Microbiol 17: 209-230.

15. Mantur BG, Biradar MS, Bidri RC, Mulimani MS, Veerappa K, Kariholu P, Patil SB, Mangalgi SS (2006) Protean clinical manifestations and diagnostic challenges of human brucellosis in adults: 16 years' experience in an endemic area. J Med Microbiol 55: 897-903.

16. Young EJ (1983) Human brucellosis. Rev Infect Dis 5: 821842.

17. Corbell MJ (1997) Brucellosis: An overview. Emerg Infect Dis 3: $213-221$.

18. Celli J (2006) Surviving inside a macrophage: the many ways of Brucella. Res Microbiol 157: 93-98.

19. Campos PC, Gomes MTR, Guimaraes G, Costa Franco MM, Marim FM, Oliveira SC (2014) Brucella abortus DNA is a major agonist to activate the host innate immune system. Microbes Infect 16: 979-984.

20. Skendros P, Pappas G, Boura P (2011) Cell-mediated immunity in human brucellosis. Microbes Infect 13: 134-142.

21. Martirosyan A, Gorvel JP (2013) Brucella evasion of adaptive immunity. Future Microbiol 8: 147-154.

22. Spink WW (1964) Host-parasite relationship in human brucellosis with prolonged illness due to suppuration of the liver and spleen. Am J Med Sci 247: 129-136.

23. Skalsky K, Yahav D, Bishara J, Pitlik S, Leibovici L, Paul M (2008) Treatment of human brucellosis: systematic review and meta-analysis of randomised controlled trials. BMJ 336: 701-704. doi:10.1136/bmj.39497.500903.25. 
24. Alavi SM, Alavi L (2013) Treatment of brucellosis: a systematic review of studies in recent twenty years. Caspian $\mathrm{J}$ Intern Med 4: 636-641.

25. Jiang $X$, Baldwin $C$ (1993) Iron augments macrophagemediated killing of Brucella abortus alone and in conjunction with interferon- $\gamma$. Cell Immunol 148: 397-407

26. Zhan Y, Cheers C (1994) Differential induction of macrophage-derived cytokines by live and dead intracellular bacteria in vitro. Infect Immun 63: 720-723.

27. Jones S, Winter A (1992) Survival of virulent and attenuated strains of Brucella abortus in normal and gamma interferonactivated murine peritoneal macrophages. Infect Immun 60: 3011-3014.

28. Jiang X, Leonard B, Benson R, Baldwin C (1993) Macrophage control of Brucella abortus: role of reactive oxygen intermediates and nitric oxide. Cell Immunol 151: 309-319.

29. Baldwin CL, Goenka R (2006) Host immune responses to the intracellular bacteria Brucella: does the bacteria instruct the host to facilitate chronic infection? Crit Rev Immunol 26: 407-442.

30. Frenchick PJ, Markaham JF, Cochrane AH (1985) Inhibition of phagosome-lysosome fusion in macrophages by soluble extract of virulent Brucella abortus. Am J Vet Res 46: 332335.

31. Kreutzer DL, Dreyfus LA, Robertson DC (1979) Interactions of polymorphonuclear leukocytes with smooth and rough strains of Brucella abortus. Infect Immun 23: 737-742.

32. Caron E, Liautard JP, Kohler S (1994) Differentiated U937 cells exhibit increased bactericidal activity upon LPS activation and discriminate between virulent and avirulent Listeria and Brucella species. J Leuk Biol 56: 174-181.

33. Latimer E, Simmers J, Sriranganathan N, Roop II RM, Schurig GG, Boyle SM (1992) Brucella abortus deficient in copper/zinc superoxide dismutase is virulent in $\mathrm{BALB} / \mathrm{c}$ mice. Microb Pathog 12: 105-113.

34. Barrionuevo P, Delpino MV, Velasquez LN, Samartino CG, Coria LM, Ibanez AE, Rodriguez ME, Cassataro J, Giambartolomei GH (2011) Brucella abortus inhibits IFN- $\gamma$ induced Fc $\gamma R$ 1 expression and Fc $\gamma R$ 1-restricted phagocytosis via toll-like receptor 2 on human monocytes/macrophages. Microbes Infect 13: 239-250.

35. Fernandes DM, Baldwin CL (1995) Interleukin-10 downregulates protective immunity to Brucella abortus. Infect Immun 63: 1130-1133.

36. Splitter G, Oliveira S, Carey M, Miller C, Ko J, Covert J (1996) T lymphocyte mediated protection against facultative intracellular bacteria. Vet Immunol Immunopath 54: 309-319.

37. Stevens MG, Pugh GW, Tabatabai LB (1992) Effects of gamma interferon and indomethacin in preventing Brucella abortus infections in mice. Infect Immun 60: 4407-4409.

38. Araya LN, Elzer PH, Rowe GE, Enright FM, Winter AJ (1989) Temporal development of protective cell-mediated and humoral immunity in BALB/c mice infected with Brucella abortus. J Immuol 143: 3330-3337.

39. Oliveria S, Splitter GA (1995) CD8+ type 1 CD44hi CD45Rblo $\mathrm{T}$ lymphocytes control intracellular Brucella abortus infection as demonstrated in major histocompatibility complex class I- and class II- deficient mice. Eur J Immunol 25: 2551-2557.

40. Khan Y, Liu Z, Cheers C (1996) Tumor necrosis factor alpha and interleukin-12 contribute to resistance to the intracellular bacterium Brucella abortus by different mechanisms. Infect Immun 64: 2782-2786.

41. Xavier MN, Winter MG, Spees AM, Nguyen K, Atluri VL, Silva TMA, Baumler AJ, Muller W, Santos RL, Tsolis RM (2013) CD $^{+}$T cell- derived IL-10 promotes Brucella abortus persistence via modulation of macrophage function. PLoS Pathog 9: e1003454. doi: 10.1371/journal.ppat.1003454.

42. Cha SB, Rayamajhi N, Kang ML, Lee WJ, Shin MK, Yoo HS (2010) Comparative study of gamma interferon production in mice immunized with outer membrane proteins and whole bacteria of Brucella abortus. Jpn J Infect Dis 63: 49-51.

43. Zaitseva M, Golding H, Betts M, Yamauchi A, Bloom ET, Butler LE, Stevan L, Golding B (1995) Human peripheral blood CD4+ and CD8+ $\mathrm{T}$ cells express Th1-like cytokine mRNA and proteins following in vitro stimulation with heatinactivated Brucella abortus. Infect Immun 63: 2720-2728.

44. Elfaki MG, Al-Hokail AA (2009) Transforming growth factor $\beta$ production correlates with depressed lymphocytes function in humans with chronic brucellosis. Microbes Infect 11: 10891096.

45. Alton GG, Jones LM, Pietz DE (1975) Laboratory techniques in brucellosis, 2nd edition. World Health Organization Monograph Series No. 55. Geneva:WHO.

46. Liang L, Leng D, Burk C, Sasaki RN, Kayala MA, Atluri VL, Pablo J, Unal B, Ficht TA, Gotuzzo E, Saito M, Morrow WJ, Liang X, Baldi P, Gilman RH, Vinetz JM, Tsolis RM, Felgner PL (2010) Large scale immune profiling of infected humans and goats reveals differential recognition of Brucella melitensis antigens. PloS Negl Trop Dis 4: e673. doi:10.1371/journal.pntd.0000673.

47. Corbell MJ (1975) The serological relationship between Brucella species, Yersinia enterocolytica serotype IX and Salmonella serotypes of Kaufmann-White group. J Hyg (Lond) 75: 151-171.

48. Diaz-Aparicio E, Martin C, Alonso-Urmeneta B, Aragon V, Perez-Ortiz S, Pardo M, Blasco JM, Diaz R, Moriyon I (1994) Evaluation of serological tests for diagnosis of Brucella melitensis infection of goats. J Clin Microbiol 32: 1159-1165.

49. Debbarh HSA, Cloeckaert A, Zygmunt MS, Dubray G (1995) Identification of sero-reactive Brucella melitensis cytosoluble proteins which discriminate between antibodies elicited by infection and Rev.1 vaccination in sheep. Vet Microbiol 44: $37-48$.

50. Harms J, Durward MA, Magnani DM, Splitter GA (2009) Evaluation of recombinant invasive, non-pathogenic Eschericia coli as a vaccine vector against the intracellular pathogen, Brucella. J Immune Based Ther Vaccines 7: 1. doi:10.1186/1476-8518-7-1.

\section{Corresponding author}

Prof. Mohamed G. Elfaki,

Department of Infection and Immunity, King Faisal Specialist Hospital and Research Centre,

P. O. Box 3354, MBC 03, Riyadh 11211, Saudi Arabia.

Phone: +966-546-271-771

Email: elfaki@kfshrc.edu.sa

Conflict of interests: No conflict of interests is declared. 